\title{
Musculação e cotidiano laboral: significados atribuídos às dores corporais em uma academia de ginástica do Rio de Janeiro
}

\author{
Resistance training and daily work routine: meanings attributed to \\ body pain in the case of a fitness center in Rio de Janeiro
}

Alan Camargo Silva (http://orcid.org/0000-0003-1729-5151) ${ }^{1}$

Jaqueline Ferreira (http://orcid.org/0000-0002-7662-1773) ${ }^{1}$

${ }^{1}$ Instituto de Estudos em Saúde Coletiva, Universidade Federal do Rio de Janeiro. Av. Horácio Macedo s/n, Ilha do Fundão. 21941-598 Rio de Janeiro Brasil. alan10@zipmail.com.br

\begin{abstract}
This article is part of an ethnographic research survey conducted over the course of a year in the resistance training sector of a fitness center located in a suburb of the city of Rio de Janeiro, the athletes of which have a low income status, and the majority of whom have professional occupations or jobs that involve a high threshold of physical effort. From the anthropological standpoint of symbolic interactionism, the main objective was to analyze how the "limits" of pain of the body related in a symbolic way to the resistance training in the fitness center and the physical efforts demanded in their professional occupations or jobs. The analysis of the observations indicated that these students perceived the body in an instrumental and utilitarian way when relating the pain of physical exercise to their daily work routines. Thus, the relationship between work and physical activities in the representations of the body "limits" of these subjects expressed through pain is implicit. These data are relevant to think about health interventions and practices in the field of Public Health.
\end{abstract}

Key words Pain, Fitness centers, Physical education and training, Work, Ethnography
Resumo Este artigo faz parte de uma pesquisa etnográfica desenvolvida durante um ano no setor de musculação de uma academia de ginástica em um bairro da cidade do Rio de Janeiro cujos alunos são de baixa renda e, em sua maioria, trabalham em ocupações ou ofícios profissionais com alta demanda de esforço físico. Através da perspectiva antropológica do interacionismo simbólico, o objetivo foi analisar em que medida os "limites" corporais relacionados às dores citadas pelos alunos na academia representavam simbolicamente as relações entre o trabalho corporal na musculação e os esforços físicos exigidos nas suas ocupações ou ofícios profissionais. As análises das observações indicaram que esses alunos concebiam o corpo de modo instrumental e utilitário ao relacionarem as dores do exercício físico ao trabalho cotidiano. Assim, fica implícita a relação entre as atividades laborais e físicas nas representações dos "limites" corporais desses sujeitos expressas através da dor. Esses dados são relevantes para se pensar as intervenções e as práticas sanitárias no campo da Saúde Coletiva.

Palavras-chave Dor, Academias de ginástica, Educação física e treinamento, Trabalho, Etnografia. 


\section{Introdução}

A noção de dor possui uma dimensão simbólica desde os tempos bíblicos e, como lembra Le Breton" "Los orígenes de la palabra pain (dolor en inglés) o pein (alemán), son en griego y latín poine (sufrir) y pcena (castigo)". A representação de dor com este sinônimo de sofrimento ou castigo já foi objeto de análise de inúmeras investigações clássicas de cunho antropológico ${ }^{2,3}$. Referenciais teórico-metodológicos da Antropologia sobre dores corporais fazem parte do cenário do campo da Saúde desde meados do século XX, em especial, a partir do período em que a Antropologia Médica começou a se constituir como um campo de saberes e de práticas ${ }^{4}$. Atualmente, parte da produção acadêmica vinculada ao corpo destina-se ao debate sobre a construção dos sentidos e dos significados relacionados à dor, à enfermidade e ao sofrimento ${ }^{5-7}$.

Alguns estudos identificaram particularidades nos usos do corpo para grupos sociais de baixa renda e/ou de trabalhadores no que diz respeito à realização de práticas corporais ${ }^{8-13}$. Entretanto, parte dessas pesquisas tangenciou as análises em torno das concepções simbólicas de dores e, sobretudo, as vinculando ao campo da Saúde. Estes trabalhos também não consideraram as dores em academias de ginástica como uma forma de "limite" corporal que pode ser modulado de acordo com os diferentes grupos e contextos sociais.

Assim, argumenta-se que as relações entre dores corporais e trabalho para grupos sociais de trabalhadores e de camadas sociais menos favorecidas podem revelar, em parte, as visões de mundo e os modos de viver desses sujeitos. Nesse caso, parte-se da perspectiva de alteridade no que diz respeito à necessidade de conhecer o outro de modo relativizado para intervir, artifício este fundamental nas práticas cotidianas do âmbito da Saúde, sobretudo no que diz respeito a grupo de trabalhadores e seus cuidados para/com/ no corpo ${ }^{14}$.

Destarte, o objetivo deste estudo foi analisar em que medida os "limites" corporais relacionados às dores citadas pelos alunos na academia representavam simbolicamente as relações entre o trabalho corporal na musculação e os esforços físicos exigidos nas suas ocupações ou ofícios profissionais. Este artigo foi derivado de uma tese de doutorado defendida no Instituto de Estudos em Saúde Coletiva da Universidade Federal do Rio de Janeiro ${ }^{15}$.

\section{Procedimentos metodológicos}

Este trabalho de caráter antropológico foi fundamentado na perspectiva do interacionismo simbólico da Escola de Chicago ${ }^{16}$. Esta pesquisa parte da abordagem teórico-metodológica que os sujeitos simbolizam as suas realidades sociais atribuindo diferentes significados a depender dos contextos e das interações cotidianas do face a face, o que podem revelar representações de uma sociedade mais ampla ${ }^{17-19}$.

Uma etnografia foi realizada no setor da musculação em uma academia de pequeno porte inserida em condições socioeconômicas e culturais consideradas populares do Rio de Janeiro, Brasil. A academia possuía um funcionário de limpeza, uma recepcionista e aproximadamente dez profissionais de Educação Física; a mensalidade custava $R \$ 55,00$ e a diária para se exercitar era de $R \$ 7,00$. O bairro onde estava localizada a academia fica na Zona Oeste da cidade carioca, região que possui baixos indicadores sociais. O local da academia ficava entre algumas residências onde vivia uma população considerada de classe média-baixa e um conjunto de favelas onde residiam famílias de diferentes graus de baixo poder aquisitivo.

Os alunos e as alunas que frequentavam a musculação estavam na faixa etária entre quinze a cinquenta anos de idade e possuíam, em média, uma remuneração em torno de um a três salários mínimos em suas ocupações e ofícios profissionais. Embora eu tenha observado tanto alunos quanto alunas, a maior parte foram alunos do sexo masculino. Em termos gerais, os homens possuíam ocupações ou ofícios profissionais como vigilantes, guardas, bombeiros, policiais, motoboys, garçons, motoristas, eletricistas, carregadores em geral, pedreiros, estofadores, mecânicos, soldadores, frentistas, etc.; e as mulheres, faxineiras, vendedoras em geral, cozinheiras, atendentes, garçonetes, costureiras, donas de casa, etc. Em consonância às ideias de Boltanski ${ }^{20}$ e de Bourdieu ${ }^{21}$, argumenta-se que pode haver habitus quanto a determinados usos do corpo em dadas circunstâncias sociais, embora exista uma multiplicidade de visões de mundo no interior das mesmas condições socioeconômicas, sobretudo em espaços urbanos onde coexiste e transita uma diversidade e complexa rede de identida$\operatorname{des}^{22}$.

Entre 2012 a 2013, com base na observação participante, a construção do diário de campo foi realizada a partir da convivência do pesquisador neste cenário com esses alunos por duas vezes na 
semana, durante quatro horas, primordialmente entre dezessete às vinte e uma horas. $\mathrm{O}$ processo de reflexividade do pesquisador, fundamental para a compreensão de um estudo qualitativo no campo da Saúde ${ }^{23,24}$, pode ser visto em Silva ${ }^{15}$.

Este estudo foi aprovado pelo Comitê de Ética em Pesquisa do Instituto de Estudos em Saúde Coletiva da Universidade Federal do Rio de Janeiro.

\section{Apresentação dos resultados}

\section{No "limite" do trabalho corporal na academia}

$\mathrm{Na}$ academia analisada, os alunos estavam constantemente no "limite" da frequência, duração e intensidade das práticas corporais. Os ritmos dos movimentos e as dinâmicas das interações sociais entre homens e mulheres na sala de musculação eram acelerados, o que impediam as conversas entre os alunos naquele espaço, ou seja, "não havia tempo a perder". As dores durante as estafas deviam ser mantidas a "qualquer custo". Na perspectiva de Goffman ${ }^{17,18}$, era possível compreender que exercitar-se desta forma representava apenas uma das maneiras de legitimar suas "fachadas" de "trabalhadores que pegavam pesado".

Grande parte dos alunos realizava os exercícios físicos na musculação e quando algum aparelho ergométrico vagasse, corriam para desfrutá -los, antes de perderem a oportunidade. Quando estavam muito cansados, voltavam a realizar outros tipos de práticas corporais que não seriam tão extenuantes. Os intervalos entre os exercícios físicos eram curtos ou inexistentes. Realizavam, em muitas ocasiões, entre cinco a seis séries de um determinado número de repetições de um único exercício ou com cargas que consideravam elevadíssimas na crença de que apenas a alta fadiga local traria os reais benefícios ao corpo. Isso propiciava dores contínuas, o que, pelo mesmo motivo, era apreciado por esses alunos. Essas referências se referiam às próprias perspectivas dos alunos e das alunas; muitas vezes, eram eles próprios que sinalizavam que o adequado para se exercitar deveria ser, por exemplo, três séries de cada movimento ou que os intervalos deveriam ser maiores, entretanto, ultrapassavam esse "limite" em busca das dores. Rodriguez ${ }^{25}$ já alertou como a experiência com a dor nas academias pode ser ressignificada ao longo do tempo ou situada em determinado contexto sociocultural.
Igualmente, o estudo de Silva e Ferreira ${ }^{26}$ identificou a pluralidade de noções de dores agudas e crônicas em academias inseridas em distintas condições socioeconômicas e culturais.

A ida ou vinda da academia era considerada um exercício físico haja vista que os alunos e as alunas imprimiam ritmos intensos ao caminharem, correrem ou andarem de bicicleta durante o percurso para a residência ou trabalho. Quando chegavam ao estabelecimento, por exemplo, começavam a se exercitar sem qualquer tipo de aquecimento ou de alongamento para não perder tempo usando o corpo de forma mais "leve". Sarti ${ }^{27}$ aponta que "Nas distinções de classe social, o sofrimento e o sentimento da dor dos despossuídos aparecem como 'naturais'”.

Alunos gritando ou gemendo eram rotineiros naqueles espaços; expressavam as dores derivadas dos esforços físicos, muitas vezes associadas com os seguintes dizeres: "Uh, que delícia!", "Ah, maravilha, como eu sofro!", “Ô, Jesus, que dor gostosa!”, etc. Parecia que tais esforços físicos eram superados por esses gemidos ou gritos, bem como pela estratégia de durante a realização dos movimentos fazer sons com os halteres causando uma poluição sonora considerável naquele espaço. Um dos alunos dizia a outro que tinha que gritar para "espantar o mal", no caso, as dores. Da mesma forma, tais sons eram também uma forma de chamarem a atenção ou de reconhecimento dos seus esforços físicos. Havia também alunos que corriam na esteira com caneleiras nos tornozelos ou nos intervalos dos exercícios físicos da musculação, de forma que estariam otimizando o trabalho corporal; eles não poderiam ficar parados. Unir o trabalho de força ao de resistência aeróbia estaria potencializando as dores no corpo no sentido de evitar riscos e ao mesmo tempo compensando o dinheiro, isto é, era uma espécie de "mais-valia no 'limite' corporal". Essas representações coadunam-se com a pesquisa de Ferreira e Magalhães ${ }^{28}$ ao identificar que determinado tipo corporal era valorizado em função do trabalho e da condição social.

Frequentemente, os alunos conversavam sobre a quantidade de horas (geralmente, mais de duas ou três horas) que estavam se exercitando ou o quanto de peso que estavam sustentando como forma de disputa de quem estava aproveitando mais o estabelecimento. Tanto da parte deles quanto delas, provocações semelhantes do tipo "você pega só isso? Pra quê?" eram recorrentes no cotidiano da musculação. Isso significava que, se fosse para "pegar leve", poderiam fazer isso fora do estabelecimento ou na academia gra- 
tuita que se localizava na praça ali das redondezas. Toda vez que eu perguntava para um aluno se já havia acabado a rotina de exercícios físicos, a resposta sempre era positiva ou que faltavam apenas alguns aparelhos de musculação a serem executados, no entanto eles permaneciam nas práticas corporais ainda por trinta minutos à uma hora, demonstrando que "podiam aguentar mais e não eram bobos de saírem 'rápidos' assim". Sinalizar que foi para a academia com apenas dez ou vinte minutos de tempo disponível para se exercitar na musculação também era outra forma do aluno demonstrar que usava o estabelecimento de forma "adequada". Não era raro um aluno perguntar o horário para o outro com o intuito de avaliar o quanto mais podiam fazer de exercícios físicos. Identificava também que os alunos mentiam sobre a frequência ao local, pois quando costumavam não aparecer por um tempo ou no horário da noite, por exemplo, alegavam que estavam vindo no turno da manhã e vice-versa. Goffman ${ }^{18}$ lembra que os sujeitos possuem consciência de quais performances podem facilitar ou prejudicar os espetáculos que encenam durante os contatos face a face nas interações sociais cotidianas.

Além disso, quando a academia não tinha fornecimento de água ou de luz, os alunos ficavam no estabelecimento como se nada estivesse os impedindo de malhar. Até mesmo quando o som era desligado por algum motivo ou quando determinado $\mathrm{CD}$ acabava de tocar, poucos eram os alunos que reclamavam de tal fato, pois estavam ali para malhar e não para ficar escutando "musiquinhas". Quando algum aparelho de musculação ficava interditado por um motivo, a princípio, simples, como um "cabo de aço fora do lugar", os próprios alunos que desejavam usá-lo se reuniam para consertá-lo, pois não pagavam uma academia "toda quebrada" para ficarem sem usar o que queriam. Se alguma peça do vestuário rasgasse durante as práticas corporais ou se até mesmo o calçado arrebentasse o solado, os alunos e as alunas continuavam a se exercitar, pois não seriam essas "coisas" que os iriam interromper na musculação.

Outro dado era que, geralmente, os alunos e as alunas argumentavam que somente valia à pena pagar a academia na época do verão e do carnaval, períodos estes onde mais exibiriam seus corpos em público e se exercitavam transparecendo compensar até o "limite" o que não malharam o ano todo. Com base em Goffman ${ }^{19}$, eu observava que as "identidades" (leia-se corporais) em determinados períodos do ano eram julgadas ou estigmatizadas. Assim, seguindo a tendência de outros cuidados do corpo quanto às estações do ano, há indícios de que as academias possuem também certa sazonalidade no que diz respeito à frequência do público.

Embora haja a noção de que as academias enchem nos períodos finais e iniciais do ano, observava uma peculiaridade ali: aqueles que tinham menores condições financeiras pagavam apenas as mensalidades nessa época de festividades, no entanto, percebia que inúmeros alunos e alunas saíam do estabelecimento, pois era um período caracterizado e conhecido por ofertas de empregos. Isto é, não podiam perder tempo ou se cansarem ao malhar no período de início e de fim de ano (dezembro, janeiro e fevereiro) para trabalharem, porque era a oportunidade de arranjarem uma ocupação fixa de carteira assinada ou até mesmo trabalhos temporários.

Assim, o público apenas trocava e o contingente de pessoas circulando por ali não aumentava significativamente. Identificava isso quando os alunos e as alunas que frequentavam de forma mais regular ao longo do ano retornavam à musculação definitivamente a partir do mês de março, período pós-festas ou do verão, afirmando que "arranjaram grandes motivos para parar com a malhação como um novo trabalho". Como no trabalho de Votre et al. ${ }^{10}$, a marca de "ser trabalhador" podia ser vista ali enquanto se exercitavam na academia.

Havia a necessidade objetiva e o valor simbólico dado ao ato de trabalhar que modulava as formas de se engajar ou não nas práticas corporais naquela academia. $\mathrm{O}$ acesso e a manutenção do ato de se exercitar, portanto, estavam implicados nas condições socioeconômicas e culturais onde os alunos estavam inseridos. Barata ${ }^{29}$ esclarece que "O fato de pertencer a uma determinada classe ou estrato social significa não apenas poder desfrutar de determinadas condições materiais, mas também acaba por moldar toda uma visão de mundo com complexas implicações para a saúde".

Nem todos os alunos que se engajavam nos "limites" corporais pagavam as mensalidades e quando o faziam, não era tão em dia. Em termos gerais, os alunos e as alunas, ao malharem no "limite" das dores dos esforços físicos em determinado estabelecimento, avaliavam os custos e os benefícios para entrar ou continuar no local. Um dos principais critérios para a escolha da academia era o valor mensal, pois constantemente observava pessoas que apenas perguntando o custo da mensalidade decidiam se ficariam no 
estabelecimento. Caso aceitassem os custos, apenas depois do pagamento, desejavam conhecer as "instalações", o que me fazia ouvir certas vezes os comentários de que "para o que era, tava bom!" e “esse valor só serve pra fazer avaliação física?”. Se não concordassem com o preço da mensalidade, grande parte das pessoas não tentava ao menos conhecer o espaço da academia. Ademais, muitas vezes, ao deparar-me com os alunos discutindo se valeria à pena trocar de academia, os argumentos tendiam a se desenvolver em torno de que a musculação deste estabelecimento era "boa e barata, além de favorecer o ganho de corpo no "limite". Assim, no primeiro mês, ao perceberem que, de imediato e por algum motivo, não estavam tendo os resultados esperados, mesmo com as altas dores provindas dos esforços físicos, os alunos migravam para outras academias, pois não poderiam "perder dinheiro" sem obter "ganhos corporais".

Assim, para esses homens e mulheres, o corpo em exercício físico na academia era o corpo do dia a dia "duro". Embora nas clivagens de gênero ainda haja a premissa universal da mulher delicada, sensível, frágil e subalterna em relação ao homem forte, viril e protetor ${ }^{27}$, na academia analisada, observava que através das dores corporais, havia a construção de identidades de "machos provedores" como também de "fêmeas provedoras". Ao mesmo tempo em que deveria tornar o corpo altamente performático, alguns "limites" poderiam ser calculados, dialogando com ideia de que as condições socioeconômicas e culturais dos alunos e das alunas eram reproduzidas durante as diferentes práticas corporais no interior daquele estabelecimento.

\section{No "limite" do trabalho corporal, na ocupação ou ofício profissional}

Para os alunos e alunas, os corpos quanto mais trabalhados no "limite" da dor, maior seria a produtividade pelo fato de o "dia render mais" e "terem mais disposição" ou do próprio reconhecimento da sua aparência no momento laboral. O investimento no "limite" das dores na musculação correspondia a uma possibilidade de ascensão social, pois o corpo trabalhado girava em torno do corpo como um instrumento de sobrevivência. Desse modo, notava que "O corpo é nas nossas sociedades um factor de individualização, modificando-o modifica-se a sua relação com o mundo. Para mudar de vida, muda-se o corpo, ou pelo menos tenta-se" ${ }^{\prime 3}$.

Um exemplo é o relato de uma vendedora que entrou na academia para "melhorar o corpo" porque sua patroa tinha exigido "emagrecer um pouco mais", critério básico esse para se trabalhar em uma loja de biquíni, segundo a "chefa”. Alguns alunos seguranças de bailes e de festas das redondezas mantinham a massa muscular porque facilitava a permanência deles no mercado de trabalho local. Outro aluno me falava que, pelo fato de dirigir ônibus cerca de dez horas e por trabalhar sentado, entrou no estabelecimento para emagrecer e se exercitar, com o objetivo de fazer mais horas extras ou "dobras" de horários.

Alguns alunos dormiam em alguns aparelhos de musculação pelas estafas laborais e das práticas corporais. Outros frequentadores entravam e saíam da academia apressadamente pelo fato de estarem atrasados para chegar aos seus trabalhos ou até mesmo às suas residências. Uma situação inusitada que presenciei foi quando uma aluna deixou o salão de beleza onde trabalhava ali das redondezas para se exercitar no estabelecimento e a cliente veio buscá-la na academia para fazer o serviço agendado. Outros alunos se engajavam nas práticas corporais visando exclusivamente concursos públicos que exigiam determinados exames ou testes físicos como a de fuzileiro naval, de gari, de guarda municipal, etc., transparecendo que o corpo era um álibi de estratégia e de fonte de sobrevivência. As formas de lidar com as dores na musculação eram um dos artifícios para os alunos se deslocarem de uma posição à outra, isto é, da instabilidade financeira ou de desemprego ao "ganha-pão 'garantido' de cada dia”.

Assim, a afirmação de identidade e de ascensão social nesta academia era por meio do corpo, capital $^{21}$ este importante no mercado de trabalho. Estar em risco ali se traduzia em perder o trabalho ou ficar desempregado, por isso, de modo simbólico e ressignificado, o corpo também era o próprio curricullum vitae do sujeito, demonstrando, de certo modo, a reprodução do status quo de uma sociedade altamente segmentada e opressora. Em outras palavras, nas relações entre escolhas subjetivas e possibilidades objetivas características do habitus ${ }^{31}$, era através do próprio corpo e de suas dores que havia a reafirmação da certa "exclusão social".

Havia inúmeros comentários dos alunos referentes aos seus trabalhos no que diz respeito à sobrecarga com que estavam se submetendo para "ganhar o pão do dia a dia", o que influenciava na rotina exaustiva de exercícios físicos. Muitos alunos relatavam que reduziram o tempo ou interromperam suas estadias na musculação pelo fato de estarem "pegados no trabalho" e com isso não conseguiam imprimir ritmos intensos nas 
práticas corporais. Outros alegavam que tinham acabado de voltar direto do trabalho, o que fazia com que eles se exercitassem com os próprios uniformes do emprego. Era possível vê-los exercitando-se com botas de operários da construção civil, crachás de estabelecimentos comerciais, uniformes de empresas terceirizadas de limpeza e roupas das atendentes de determinadas lojas, por exemplo. Algumas vezes, abreviavam a quantidade de exercícios físicos porque teriam que "bater ponto" mais cedo no trabalho, reduzindo, assim, as possibilidades de alcançarem determinados limiares de dores durante as práticas corporais.

Nesses casos, o aluno se sentia em risco caso continuasse com a mesma rotina de malhação: "O meu trabalho está me atrapalhando para cuidar melhor de mim, não consigo pegar pesado como eu fazia!", "Queria malhar mais, mas tô fudido de tanto trabalho!", "O trabalho tá sinistro! Acho que vou ter que deixar a academia!", "Deixei de fazer a aula porque tinha um compromisso com um cliente!", etc., eram alguns exemplos de falas que justificavam em muitas das oportunidades não estarem malhando no "limite" das dores dos esforços físicos. Tais relatos eram mais frequentes após os finais de semana ou feriados, períodos estes que diziam trabalhar mais, pois ganhavam um dinheiro extra com o lazer dos outros como, por exemplo, vender comidas e bebidas na praia, em festas ou em eventos à noite, fazer a "dobra" na loja para ganhar mais comissão, realizar trabalhos relacionados à construção civil para algum conhecido em seus dias de folga, acordar de madrugada para comercializar algo na feira, etc.

Assim, o trabalho servia como uma "desculpa" socialmente bem aceita por todos ali de que não estavam chegando aos limites das práticas corporais, já que naqueles grupos sociais que faziam parte da academia o "ser trabalhador" era hipervalorizado por demonstrar responsabilidade do sujeito. Essa responsabilidade se dá pela ideia-valor do sacrifício, este atrelado a vida do trabalhador em que é constituída por dificuldades de reprodução material, expressas na luta e na batalha cotidiana de condições mínimas de sobrevivência ${ }^{32}$. Zaluar ${ }^{33}$ identificou que "[...] o termo trabalhador é sempre dito com orgulho, se a fala é auto-referida, ou uma ponta de respeito, se a fala se refere a outrem".

Baseando-me em Le Breton ${ }^{34}$, parecia haver um bom e um mau cansaço na medida em que estar no total "limite" corporal somente era aceito se o sujeito estivesse plenamente exausto das suas atividades laborais, caso contrário, era posto em um lugar inferior àqueles que frequenta- vam o estabelecimento. Nesse sentido, entendia que o ato de se alcançar determinados "limites", relativos aos esforços físicos provindos das práticas corporais na musculação, fazia parte de um drama social ${ }^{18}$ maior que começava ou terminava no próprio cotidiano do trabalho relacionado à ocupação ou ao ofício profissional. Assim, as interações sociais entre os alunos e as alunas apontavam que as identidades deles se concretizavam em grande parte pelo ato de sentir dores na academia até o local de trabalho ou vice-versa.

Raros alunos dali compartilhavam a ideia de que as dores relacionadas aos esforços físicos não eram tão necessárias para um bom rendimento da prática da malhação e não relacionavam a noção de corpo no "limite" para o trabalho ou para compensar os custos da mensalidade. As dramatizações em se engajar nas práticas corporais no "limite" das dores, portanto, variava entre os grupos sociais da academia, isto é, nem todos possuíam ou assumiam da mesma forma os seus "limites". Tais alunos que se destoavam dos demais, por temporariamente estarem nos "interstícios", "à margem" ou "em degraus mais baixos" daqueles grupos sociais, passavam por uma série e distintas provações, no sentido de se alinharem ou não aos outros que estimulavam os "limites" corporais. Assim, as identidades dos alunos e das alunas também iam se modificando substancialmente no interior da musculação na medida em que a noção de "limites" corporais era construída pelos diferentes grupos e situações sociais. Nas palavras de Crossley ${ }^{35,36}$, diante de diferentes formas de modificar ou cultuar o corpo, criava-se ali uma "carreira" de como ser um praticante de musculação.

\section{Conclusões}

Foi possível perceber que os "limites" das dores dos alunos quando se exercitavam na musculação desta academia de ginástica popular do Rio de Janeiro estavam relacionados aos seus "limites" laborais. Durante as interações sociais do face a face, os alunos não distinguiam as relações entre o trabalho corporal na musculação e o trabalho da ocupação e do ofício profissional, isto é, as estafas das práticas corporais estavam simbolicamente atreladas aos esforços físicos realizados nas atividades laborais.

Assim, a academia assumia essencialmente uma espécie de "sobrevivência" em que o corpo era um dos únicos ou o principal "instrumento" para se impor aos outros ou se distinguir do seu 
grupo social. Isto é, havia "trabalho" e "trabalhos": o trabalho corporal na musculação estava no mesmo nível ou diretamente intricado ao trabalho da ocupação e do ofício profissional na medida em que os "movimentos do corpo" proporcionavam "movimentos positivos na vida".

Grande parte dos alunos se exercitava no "limite" da frequência, duração e intensidade dos exercícios físicos. Seja por um fator objetivo referente às condições financeiras e/ou subjetivo de ordem simbólica, era possível perceber a importância e a valorização da dor no trabalho corporal e/ou laboral para os grupos sociais dali. A vida dos alunos e das alunas fora e dentro da academia era regida por um exercício diário de dores, trabalhos e "limites" corporais, haja vista as condições socioeconômicas e culturais onde eles estavam inseridos.

Portanto, estas performances dos alunos no sentido do culto ao trabalho corporal no "limite" das dores na musculação reproduziam os desempenhos valorizados ou exercitados em suas ocupações e ofícios profissionais. O corpo da academia era o corpo da vida cotidiana árdua financeiramente envolvida por uma série de elementos vinculados ao "ser trabalhador ou trabalhadora”. A dor corporal no interior da academia representava ou dialogava, em parte, com a dor da vida fora daquele estabelecimento. Assim, grande parte das identidades construídas ali entendia que o grau de "limite" da dor era apenas um dos parâmetros que mensuraria o nível de vida - leia-se socioeconômica ou corporalmente.

Para além do foco hospitalocêntrico, recomendam-se mais investigações no campo da Saúde no sentido de aprofundarem as relações entre corpo e dor que podem variar amplamente em populações consideradas de baixa renda e/ ou de trabalhadores. Tanto para a intervenção ou para as práticas em saúde, compreender essas particularidades dos usos do corpo e as noções de dor nesses grupos sociais auxilia sobremaneira na relação entre o profissional de saúde e os usuários nos serviços de saúde ${ }^{37}$.

\section{Colaboradores}

AC Silva foi responsável pelo trabalho de campo e desenvolvimento de todas as etapas da pesquisa. J Ferreira foi responsável pela revisão crítica do conteúdo orientando em todas as etapas do estudo, bem como pela aprovação da versão final deste manuscrito. 


\section{Referências}

1. Le Breton D. Antropología del dolor. Barcelona: Seix Barral; 1999.

2. Zborowski M. Cultural components in responses to pain. J Soc Issues 1952; (8):16-30.

3. Zola IK. Culture and symptoms: an analysis of patients presenting complaints. Amer Sociol Rev 1966; (31):615630.

4. Saillant F, Genest S, organizadores. Antropologia médica: ancoragens locais, desafios globais. Rio de Janeiro: Fiocruz; 2012.

5. Moreno-Altamirano L. Reflexiones sobre el trayecto salud-padecimiento-enfermedad-atención: una mirada socioantropológica. Salud Publica Mex 2007; 49(1):6370.

6. Marín RZ. La enfermedad y el sentido del sufrimiento. Rev Cubana Salud Publica 2009; 35(1):1-5.

7. Ortega-Bolaños JA, Bula-Escobar JI. El cuerpo como escenario de vulnerabilidad social en salud. Rev Salud Publica 2012; 14(6):1037-1046.

8. Iriart JAB, Andrade TM. Musculação, uso de esteróides anabolizantes e percepção de risco entre jovens fisiculturistas de um bairro popular de Salvador, Bahia, Brasil. Cad Saude Publica 2002; 18(5):1379-1387.

9. Robledo-Martínez R. Características socioculturales de la actividad física en tres regiones de Colombia. Rev Salud Publica 2006; 8(Supl. 2):13-27.

10. Votre SJ, Vigne JA, Lacerda Y. Mulheres da Rocinha: relações entre corpo, identidade e trabalho. Movimento 2008; 14(3):53-69.

11. Iriart JAB, Chaves JC, Orleans RG. Culto ao corpo e uso de anabolizantes entre praticantes de musculação. Cad Saude Publica 2009; 25(4):773-782.

12. Wacquant $\mathrm{L}$. Whores, slaves and stallions: languages of exploitation and accommodation among boxers. Body Soc 2001; 7(2-3):181-194.

13. Freitas DC, Silva FAG, Silva AC, Lüdorf SMA. As práticas corporais nas academias de ginástica: um olhar do professor sobre o corpo fluminense. Rev Bras Ciênc Esporte 2011; 33(4):959-974.

14. Menendez EL. El modelo médico y la salud de los trabajadores. Salud Colectiva 2005; 1(1):9-32.

15. Silva AC. "Limites" corporais e risco à saúde na musculação: etnografia comparativa entre duas academias de ginástica cariocas [tese]. Rio de Janeiro: Instituto de Estudos em Saúde Coletiva; 2014.

16. Becker H. A escola de Chicago. Mana 1996; 2(2):177188.

17. Goffman E. Ritual de la interacción. Buenos Aires: Tiempo Contemporáneo; 1970.

18. Goffman E. La presentación de la persona en la vida cotidiana. Buenos Aires: Amorrortu; 1981.

19. Goffman E. Estigma: la identidad deteriorada. Buenos Aires: Amorrortu; 2006.

20. Boltanski L. Los usos sociales del cuerpo. Buenos Aires: Periferia; 1975.

21. Bourdieu P. Sociologia. São Paulo: Ática; 1983.
22. Velho G. Antropologia urbana: encontro de tradições e novas perspectivas. Sociologia (Lisb. Impr.) 2009; (59):11-18.

23. Trad LAB. Trabalho de campo, narrativa e produção de conhecimento na pesquisa etnográfica contemporânea: subsídios ao campo da saúde. Cien Saude Colet 2012; 17(3):627-633.

24. Minayo MCS, Guerriero ICZ. Reflexividade como éthos da pesquisa qualitativa. Cien Saude Colet 2014; 19(4):1103-1112.

25. Rodriguez AD. Si te duele es porque estás entrenando bien. La sensación paradójica de dolor corporal en los gimnasios de fitness de la Ciudad Autónoma de Buenos Aires. Movimento 2017; 23(2):743-754.

26. Silva AC, Ferreira J. Corpos no "limite" e risco à saúde na musculação: etnografia sobre dores agudas e crônicas. Interface (Botucatu) 2017; 21(60):141-151.

27. Sarti CA. A dor, o indivíduo e a cultura. Saude Soc 2001; 10(1):3-13

28. Ferreira VA, Magalhães R. O corpo cúmplice da vida: considerações a partir dos depoimentos de mulheres obesas de uma favela carioca. Cien Saude Colet 2006; 11(2):483-490.

29. Barata RB. Como e por que as desigualdades sociais fazem mal à saúde. Rio de Janeiro: Editora Fiocruz; 2009.

30. Le Breton D. Sinais de identidade: tatuagens, piercings e outras marcas corporais. Lisboa: Miosótis; 2004.

31. Montagner MA. Pierre Bourdieu, o corpo e a saúde: algumas possibilidades teóricas. Cien Saude Colet 2006; 11(2):515-526.

32. Guedes SL. Jogo de corpo: um estudo de construção social de trabalhadores. Niterói: EDUFF; 1997.

33. Zaluar A. A máquina e a revolta: as organizações populares e o significado da pobreza. São Paulo: Brasiliense; 1984.

34. Le Breton D. Antropología del cuerpo y modernidad. Buenos Aires: Nueva Visión; 2002.

35. Crossley N. Mapping reflexive body techniques: on body modification and maintenance. Body Soc 2005; 11(1):1-35.

36. Crossley N. In the gym: motives, meaning and moral careers. Body Soc 2006; 12(3):23-50.

37. Ferreira J. Prefácio. In: Silva AC. Corpos no limite: suplementos alimentares e anabolizantes em academias de ginástica. Jundiaí: Paco Editorial; 2017. p. 11-15.
Artigo apresentado em 18/10/2017

Aprovado em 06/04/2018

Versão final apresentada em 08/04/2018 